\title{
Truck Driver Dies When Tractor-Trailer Overturns After Leaving Road
}

\author{
Incident Number: 12KY011
}

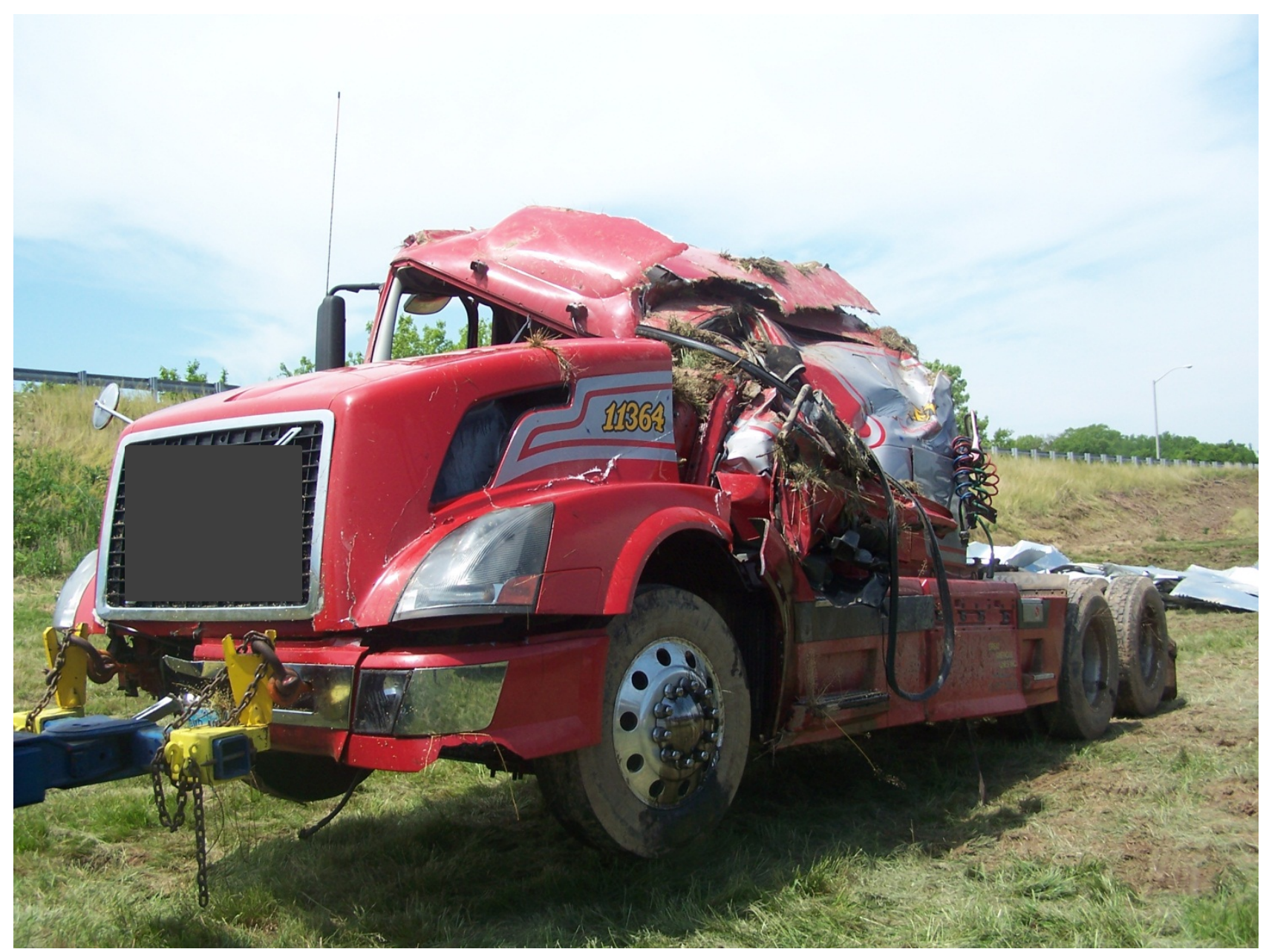

The tractor involved in the crash. Photograph property of KY FACE program

Kentucky Fatality Assessment and Control Evaluation Program Kentucky Injury Prevention and Research Center 333 Waller Avenue

Suite 242

Lexington, Kentucky 40504

Phone: 859-323-2981

Fax: 859-257-3909

www.kiprc.uky.edu

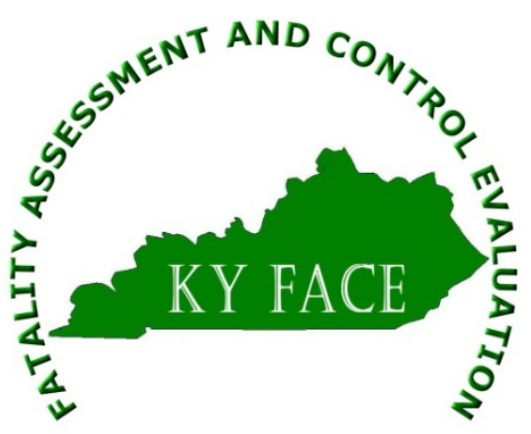




\title{
Kentucky Fatality Assessment and Control Evaluation (FACE) Program Incident Number: 12KY011 Release Date: May 14, 2013 Subject: Truck Driver Dies When Tractor-Trailer Overturns After Leaving Road
}

\begin{abstract}
Summary
In the early morning hours of a spring day around 5:45 a.m., a 55-year-old male truck driver was driving south on an interstate transporting sheet metal. It is unknown how long he had been driving when he exited from the highway, traveled partially up the ramp, and struck the left side guard rail. The truck left the road, traveled down an embankment and overturned onto its roof. A passing motorist called emergency medical services. The driver was extricated by mechanical means and declared dead at the scene.
\end{abstract}

To prevent future occurrences of similar incidents, the following recommendations have been made:

Recommendation No. 1: Employers should provide training to drivers on the importance of being attentive and not engaging in distracting tasks or behaviors while driving.

Recommendation No. 2: Semi tractor-trailer drivers should be trained to recognize signs of fatigue and drowsiness and when to seek appropriate rest areas.

Recommendation No. 3: Places for truck drivers to stop and rest should be located at regular intervals along interstates that are heavily traveled by trucks.

\section{Background}

The driver was an owner/operator leased to a transportation company. Classified as an interstate company, the company had 536 power units and 495 drivers that transported a variety of materials including sheet metal, building material, and machinery. The driver was employed by a regional carrier leased to this larger company. The regional carrier specialized in transporting steel and aluminum in covered wagons. The type of safety program employed by this company was unknown. The driver was employed as a truck driver after retiring from a dispensing equipment manufacturing company five years prior to the crash. It is not known how long he had been a truck driver or if his previous employment involved driving trucks.

On the day of the incident, the temperature ranged from 50 to 60 degrees Fahrenheit in the early morning and there was no precipitation. 


\section{Investigation}

The Kentucky Fatality Assessment and Control Evaluation Program was notified of an occupational fatality involving an operator hauling sheet metal. Interviewed for this report was the responding sheriff's deputy. A site visit was made the day of the incident and photographs were taken.

On a spring afternoon, around 3:30 p.m., a 55-year-old owner/operator driving a 2006 semi began pulling a "side kit" Conestoga covered wagon loaded with sheet metal. The driver was headed to a destination approximately 460 miles southwest. The cargo was scheduled to be delivered by 10:00 a.m. the next morning, allowing 19 1/2 hours (a time zone would be crossed) for a $7 \frac{1}{2}$ hour trip.

By 5:45 a.m. the next day, 14 hours after starting, the driver had reached a point approximately 300 miles into his trip. Since the driver had only driven 300 miles in 14 hours, he is presumed to have stopped at some point during the night but the specific details are unknown. He was traveling south on a four lane divided interstate and the speed limit was 70 miles per hour when he approached an exit. The road conditions were dark but the interstate and exit ramp were lighted. The pavement was concrete and it was wet.

The driver exited the interstate and began to travel up the exit ramp. While traveling on the ramp, the truck struck the left side guard rail and continued off the road. The truck traveled down an embankment and overturned onto its roof at approximately 5:50 a.m. According to the police report, the driver was restrained and there was no evidence of braking at any point. Two sections of the guardrail and five support posts were damaged in the collision.

A passing motorist witnessed the incident and called Emergency Medical Services. The driver had to be extricated by mechanical means and was declared dead at the scene.

Sheriff's deputies could not determine if the driver was trying to negotiate the ramp and was unsuccessful or if he lost control for some other reason. Test results on the driver indicated he had not been drinking or using any controlled substances. A heart attack was also ruled out as a causal factor in the crash. Speed was not listed as a factor. The damage to the tractor and trailer was noted to be very severe.

\section{Cause of Death}

The cause of death was blunt force trauma due to a motor vehicle crash.

\section{Recommendations and Discussions}

Recommendation No. 1: Employers should provide training to drivers on the importance of being attentive and not engaging in distracting tasks or behaviors while driving. 
The driver involved in this incident did exit the interstate and was negotiating the exit ramp when he lost control of his vehicle for an unknown reason. A medical event was ruled out as a causal factor and the lack of skid marks at the scene indicates that either distraction/inattention or sleepiness/fatigue may have played a role in the fatal collision. Commercial motor vehicle drivers should be reminded not to engage in distracting tasks or behaviors. Even routine types of behaviors such as reaching for an object, putting on sunglasses, or reaching for food can be distracting and could lead to safety critical events. Drivers should maintain two-hands steering contact while driving. Fleet safety managers should also be aware of the types of devices that CMV drivers may bring in the truck cab while driving. Even devices that seem harmless, such as calculators, have been found to increase crash risk if used while driving. Devices such as phones that have to be manually handled, personal tablets, and laptop computers should not be used while driving. These devices are only appropriate to use when the driver has pulled over and is stopped.

\section{Recommendation No. 2: Semi tractor-trailer drivers should be trained to recognize signs of fatigue and drowsiness and when to seek appropriate rest areas.}

Fatigue is one of the main occupational hazards commercial drivers face. Commercial drivers must be educated to recognize signs of fatigue. According to an article, "Driver Fatigue: The Dangers of Driving Sleepy," signs of driver fatigue include daydreaming, straying out of the lane, excessive yawning, feeling impatient, reacting slowly and/or stiff, heavy eyes. Methods to avoid driver fatigue include getting enough sleep, taking breaks every two hours in places where the driver could take a nap, eating a snack, staying hydrated, avoiding consumption of alcohol, and having a driving plan. Lack of braking action may have indicated that fatigue was a factor in this crash.

\section{Recommendation No. 3: Places for truck drivers to stop and rest should be located at regular intervals along interstates that are heavily traveled by trucks.}

Truck drivers must have appropriate places to stop and rest and they must be able to locate these parking spaces when they need them. According to a 2005 report by the U.S. Department of Transportation, there is both a shortage of parking spaces for truck drivers as well as difficulty in them locating parking that is available. Conversations with a sheriff's deputy particular to this incident indicated that there may not have been adequate truck stops on the interstate that was being traveled. In fact, it was noted that truck drivers frequently park on the shoulders of the exit ramp to sleep, creating an unsafe situation for the drivers as well as other motorists using the same roads. The Department of Transportation report confirmed that the state where this incident occurred does have a shortage of parking spaces for truck drivers. This report also reinforced the recommendation of a 2002 Federal Highway Administration study, in which the FHWA recommended developing "Intelligent Transportation Systems deployments to provide commercial motor vehicle drivers with real-time information on the location and availability of parking spaces." With such a system, truck drivers would be able to locate available parking spaces in appropriate rest areas when they need them. 


\section{Keywords}

Driver distraction

Driver fatigue

Truck parking

\section{References}

http://www.distraction.gov/research/PDF-Files/Driver-Distraction-Commercial-VehicleOperations.pdf

http://www.sleep-deprivation.com/articles/causes-of-sleep-deprivation/driver-fatigue.php http://www.rta.nsw.gov.au/roadsafety/fatigue/index.html

http://www.fmcsa.dot.gov/facts-research/research-technology/report/intelligent-transportationtruckparking.htm

\section{Acknowledgements}

The Kentucky FACE program would like to thank the local police department and the towing company for their assistance with this report.

The Kentucky Fatality Assessment \& Control Evaluation Program (FACE) is funded by grant 2U60OH008483-09 from the Centers for Disease Control and the National Institute of Safety and Health. The purpose of FACE is to aid in the research and prevention of occupational fatalities by evaluating events leading to, during, and after a work related fatality.

Recommendations are made to help employers and employees have a safer work environment. For more information about FACE and KIPRC, please visit our website at: www.kiprc.uky.edu 


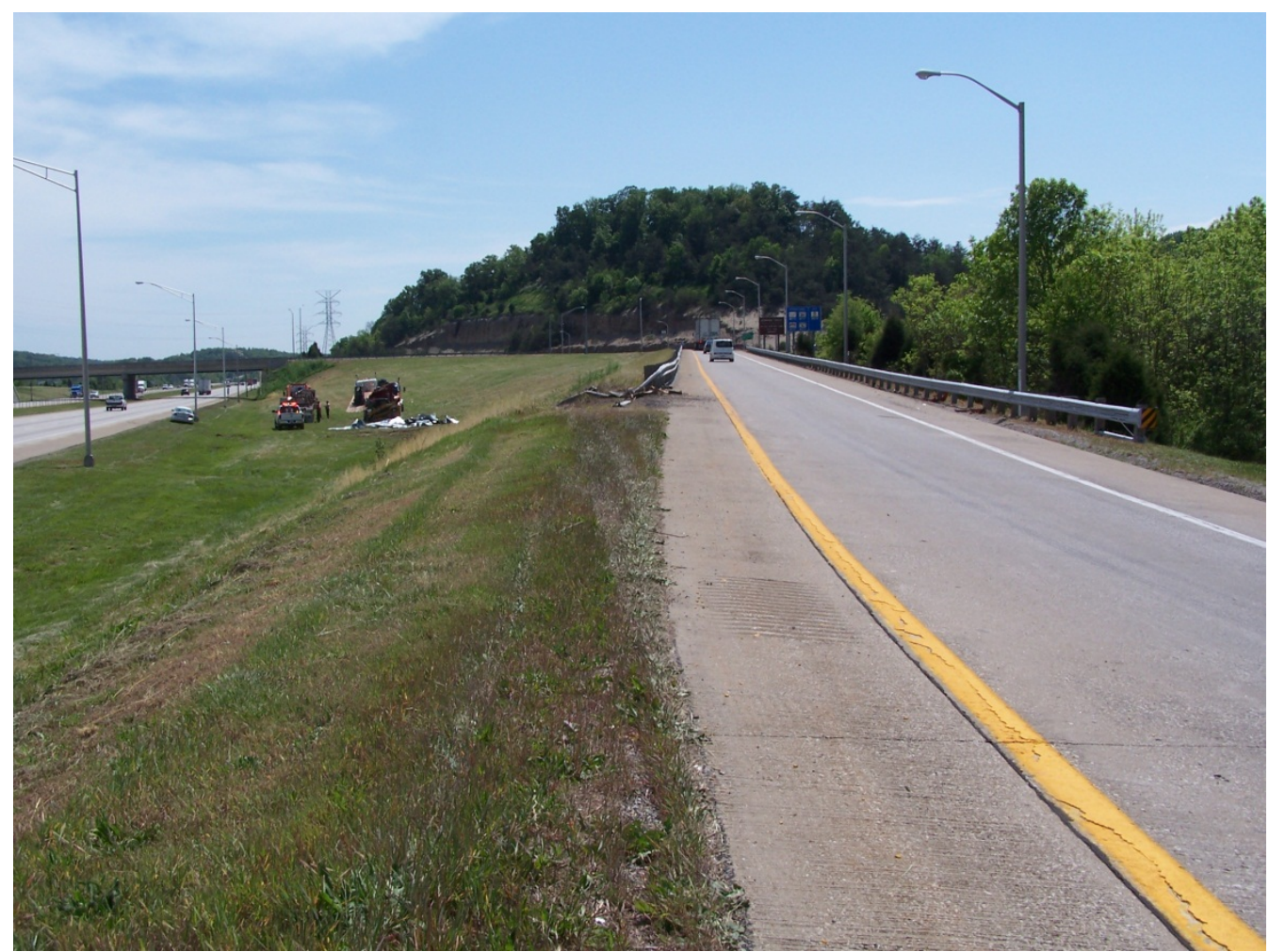

The exit ramp where the tractor-trailer left the road. Property of KY FACE

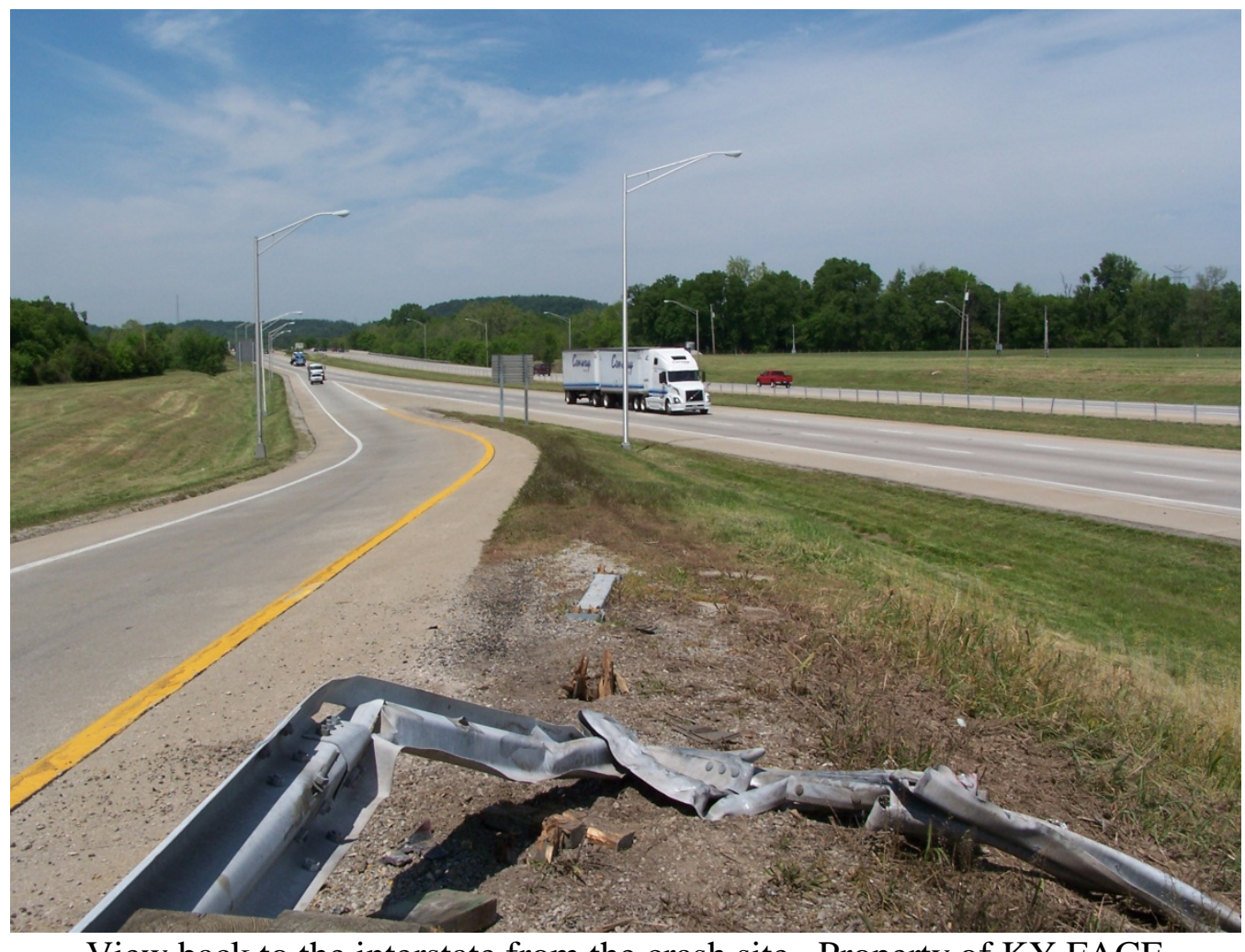

View back to the interstate from the crash site. Property of KY FACE 